\title{
Cengestao
}

\section{Tecnicidade, teoria da informação e tradição no movimento zapatista de libertação nacional: das potências de um novo mundo (informacional) possível}

\author{
Bianca Rihan Amorim \\ Doutoranda: Instituto Brasileiro de Informação em Ciência e Tecnologia, Rio de Janeiro, RJ, Brasil \\ biarihan@hotmail.com \\ Gustavo Silva Saldanha \\ Doutor:, Instituto Brasileiro de Informação em Ciência e Tecnologia, Rio de Janeiro, RJ, Brasil \\ saldanhaquim@gmail.com
}

\begin{abstract}
Resumo: A partir de uma reflexão teórica com um aporte empírico de compreensão do mundo social, o trabalho procura colocar em jogo as questões que norteiam os polos da tecnofobia à tecnofilia, ou à pan-técnica, na contemporaneidade. Partindo centralmente da filosofia de Simondon, o eixo teórico visa a compreender uma noção de técnica orientada pela primazia dos encontros e para a infinidade da diversidade nos eventos de dentro e fora, que aparecem e desaparecem sucessiva e simultaneamente no plano informacional. Uma teoria simondoniana "da informação" nos abre as margens de composições capazes de produzir quaisquer configurações para os devires - potência geradora da vida, ou seja, a tessitura entre proximidades e afastamentos, matéria e energia que constantemente atravessam-se e atualizam-se nos esteios da individuação de humanos e não humanos. O eixo empírico encontra na experiência zapatista, ou seja, na produção de uma guerrilha autonômica, uma relação original e aberta, como a visão simondoniana da técnica, que não mantém o passado précapitalista nem as estruturas pré-modernas de forma intocável. Trata-se de reconhecer a tecnomagia como possibilidade de investigação no âmbito da interpenetração entre tecnologia e cosmovisões, um movimento teórico-social de uma comunidade em sua luta contra a dominação e contra a opressão institucionalizada.
\end{abstract}

Palavras-chave: Tecnicidade. Informação. Simondon. Movimento Zapatista. Tecnomagia.

\section{Introdução}

Desviando de concepções tecnofóbicas, que avaliam os objetos técnicos a partir de um domínio exclusivamente predador, mas também refutando concepções tecnofílicas, que supervalorizam esses mesmos objetos quanto às suas possibilidades de "salvação" da humanidade, pretendemos apresentar a 
experiência do Movimento zapatista de libertação nacional - estabelecido nas montanhas do sudeste mexicano, mais precisamente no estado de Chiapas - e seu cortejo elástico entre variáveis sociais e maquínicas na produção de uma crítica original às capturas tecnológicas do capitalismo globalizado e homogeneizante.

As questões que norteiam os polos da tecnofobia à tecnofilia ou à pantécnica, um governo pautado no amor às impressões retiradas de algoritmos, como a falível "intencionalidade" do big data pode sugerir, provêm da Antiguidade, na preocupação platônica com as técnicas do discurso e o papel de uma maquinaria antecedendo a razão. Mais perspicaz na observação crítica da técnica, a visão aristotélica procurava, desde ali, perceber que não nos livraríamos, pelo exercício da razão, da condicionante da técnica. O principal ato racional sobre uma tecnicidade deveria, deste modo, primeiramente, concebê-la enquanto tal, um objeto (também da filosofia), e, para tal, necessário à reflexão, e também à própria sociedade. Em linhas mais objetivas, tratava-se de questionar o papel secundário ou igualmente central da poiesis (a arte da criação) dentro do quadro objetal filosófico.

Diferentes filósofos, ao longo do percurso de mais de dois mil anos, retomaram a dicotomia de uma mediação humana vs uma mediação técnica. Apesar de diferentes contribuições medievais, a luz do neoplanotismo impediu o aprofundamento de um debate sobre a elaboração e o uso de técnicas no seio social. É com a retomada aristotélica pós Tomás de Aquino, no século XIII, que, por sua vez, na direção contrária, o silêncio sobre a técnica se torna um dos problemas centrais nos primeiros indícios da Modernidade, compreendida, dentre outras possibilidades, como a era de uma devoção deliberada ao potencial de criação e de apropriação do virtus maquínico visando à transformação do homem. Segundo o vocabulário derridiano (DERRIDA, 2008), tais percepções vinculam-se aos problemas da mediação, de um lado ligados às "mediações da presença" (que reúnem a filosofia platônica e os métodos antropológicos dos últimos duzentos anos, vinculados à "paixão" por uma "ciência do face-a-face"), de outro, liga-se às "mediações da ausência" (baseadas na técnica como substituta primeira do homem nas relações sociais). 
Resulta, deste longo processo, uma lista de significados e de repercussões da noção de técnica, criticamente repertoriados por Vieira Pinto (2005), tendo uma de suas máximas expressões na abordagem wieneriana, com sua cibernética. Como Vieira Pinto (2005) argumenta, no percurso histórico, podemos compreender do surgimento de uma razão técnica ao uso da técnica como principal arma de dominação, levando-nos a uma racionalização como uma ideologia da técnica.

Ao mesmo tempo, o filósofo da tecnologia destaca como diferentes mitos e problemas sócio históricos, como a revolução industrial, construíram distintas maneiras de "desumanizar a técnica" (VIEIRA PINTO, 2005, p. 400), tornando-a inimiga, primeiro, do desenvolvimento social e das lutas por igualdade. Trata-se do surgimento da grande figura do "espantalho da técnica" (2005, p. 402), ou ainda, o espantalho do "terror tecnológico" (2005, p. 403) que, iniciado no século XVIII, desdobra-se até a "revolução cibernética" e não cessa. No entanto, é justamente sob a reflexão do assombro da invenção do "espantalho" e de sua escatologia que se constitui uma noção aberta, não ingênua, da técnica, flexível a ponto de perceber seus usos na concretude dos problemas das classes sociais e dos dilemas da desigualdade.

A partir de tais reflexões iniciais para este percurso teórico, partimos do aporte de Simondon (2008), Deleuze e Guattari (1997), com o intuito de discutir um modo distinto de apropriação da técnica e de (re)dimensionamento de seu papel no contexto social. Trata-se de abordar o protagonismo zapatista em ações coletivas, que se relacionam aos objetos técnicos de modo a libertá-los das clausuras do "espantalho". A partir de apropriações criativas da tecnologia, surgem interessantes possibilidades para a produção de um novo mundo possível.

Em outros termos, trata-se de pensar uma cultura das técnicas no contexto informacional como formas de resistência e exploração máxima do conteúdo do discurso de cada comunidade. A informação, compreendida aqui como potência verbal ou a verbal manifestada nos mais diferentes cenários, consolida, pois, a força refratária ao aniquilamento das diferenças. De trama anti-wieneriana, a informação aqui se coloca na fronteira negada pelo 
mecanicismo: contra toda e qualquer deslegitimação da técnica do outro, é a gramática potente que faz da alteridade parte do todo, e não redução.

\section{Os indivíduos modernos}

Como se sabe, o chamado pensamento moderno constituiu-se a partir das ideias de racionalidade e de cientificidade, intitulando-se conhecimento superior em relação aos tantos e diversificados saberes espalhados ao redor do mundo. Nessa contenda, a chamada razão moderna tratou de desenvolver sua própria escala “civilizatória” em que natureza e ciência ocupam polos antagônicos.

Àqueles povos não europeus, considerados não cultos e próximos à natureza, seria logo atribuída a designação de selvagens, ao passo que aos europeus - ilustrados e racionais - dava-se a nobre missão de civilizá-los.

Assim, a invenção do pensamento moderno, aclamado pensamento universal, estabeleceu-se pela interdição de outras formas de enxergar a existência, de vivenciar o tempo, o espaço e as relações - sejam relações entre pessoas e suas subjetividades; sejam relações entre pessoas e a materialidade dos objetos que as cercam. O mundo da "ciência moderna", com suas certezas absolutas e explicações finalizadoras acabou, portanto, por excluir da realidade humana e também dos objetos técnicos suas propriedades dinâmicas, em movimento, relação e transformação.

Ao passo em que a construção científica, pautada pela retórica da "verdade objetiva", desprezou as diferentes cosmovisões que há muito se dedicam a entender o mundo, seus representantes, corpos "não iluminados", foram sendo transformados em animais, e só aproximados às máquinas ao assumirem função estritamente servil: diferentemente do que nos ensinou a escola ocidental de tradição europeia, não foi a máquina a vapor a tecnologia inaugural dos tempos modernos, mas os homens e mulheres excluídos, renegados, explorados, que seriam responsáveis pelo trabalho (re)produtivo (PRECIADO, 2014).

Logo, se a Modernidade fundou o humanismo, ela também forjou o contraindivíduo humano: negros, índios, mulheres, homossexuais; corpos desviantes do sujeito consagrado, branco, macho, heterossexual, asséptico. E, 
assim, os contraindivíduos, ora animalizados, ora maquinizados - máquinas vivas duramente cronometradas -, vir-se-iam destinados a produzir o prazer e a liberdade daqueles que lhes roubaram:

Mas o sujeito vaza por todos os lados. As feministas não cansam de nos lembrar que o retrato canônico do sujeito que posa como abstrato, universal, racional, reflexivo evoca - coincidência? - um membro típico de um subconjunto particular do gênero masculino. Os estudos culturais sobre raça e etnia denunciam, de forma insistente, as relações espúrias entre o sujeito que é privilegiado no discurso e nas instituições dominantes, e o homem branco, de ascendência europeia. A análise pós-colonialista, por sua vez, flagra o sujeito racional e iluminado em suspeitas posições que denunciam as complexas tramas entre desejo, poder, raça, gênero e sexualidade em que ele se vê, inevitável e inequivocamente, envolvido. Reunidas, essas teorias mostram que não existe sujeito ou subjetividade fora da história e da linguagem, fora da cultura e das relações de poder. Sobra alguma coisa? (TADEU, 2009, p. 9-10).

A condição do "claustro" do sujeito no social e na linguagem, no contexto da Modernidade Ocidental, merece ainda dois aprofundamentos críticos: a ambiguidade da noção de humanismo tomada como um real do homem; e o sagrado como objeto primeiro da ciência ocultado pela exacerbação do racional sobre o real. No primeiro caso, a noção de "humanismo" comporta menos a centralidade no homem, e, justamente, a verticalidade na técnica (dada por uma clara economia da linguagem, ou economia política do discurso). Como lembra Vieira Pinto, “O nome Revolução Industrial é por antonomásia mais uma das comendas que a si mesmo se atribuiu o império britânico.” (2005, p. 403). Em outros termos, dando continuidade à superestrutura ética da Igreja Protestante, Deus é reposicionado (e não assassinado), as condições morais se adaptam (mas não morrem), e a técnica ocupa um lugar decisivo (uma outra superestrutura em rápido avanço).

Por sua vez, no plano epistemológico, o falso abandono do "mito filosófico", ou o "mito da metafísica", na visão dos "modernos", em prol de uma "consciência da razão", ou a prevalência da razão sobre o todo, demonstra o movimento contrário em sua teleologia. Ao máximo estágio de racionalização completa do filosofar (inclusive para além da técnica), compreendido a partir da 
Física Social de August Comte e subsequente movimento positivista, resulta justamente em uma mitificação deliberada.

A ciência só atinge sua forma própria na medida em que expurga todos os componentes míticos e metafísicos. Contudo, justamente a evolução da doutrina de Comte mostra que precisamente os momentos e motivos que ela acreditou ter atravessado já em seu início, nela continuam vivos e atuantes. O próprio sistema de Comte, que começou desterrando tudo o que era mítico para os primórdios e para a pré-história da ciência, culmina numa superestrutura mítico-religiosa. (CASSIRER, 2004 , p. 8 , grifo nosso).

Demonstra-se, com isto, que nem um percurso (um "humanismo de fato humano"), nem outro (uma razão acima de todo o mito, incluindo o mito das técnicas), se colocada como explicação plausível para o real e para as condições sociais do homem, muito menos nos permite perceber a complexidade das relações entre os indivíduos e seus objetos técnicos, problematizados por Simondon.

\section{Os indivíduos e os objetos técnicos}

Contraditoriamente, vamos entendendo como a colonização, a escravidão e a servidão funcionaram como forças motrizes de seu tripé antitético, que alardeava a invenção do indivíduo moderno sob o bastião da "liberdade, igualdade e fraternidade".

Conforme ressalta Beatriz Preciado (2014), se animais e pessoas são, há muitos séculos, tratados como máquinas, contemporaneamente as máquinas vão se tornando cada vez mais "tecnoanimais vivos entre os animais tecnovivos: a máquina e o animal (migrantes, corpos farmacopornográficos, filhos da ovelha Dolly, cérebros eletrodigitais) se constituem como novos sujeitos políticos" (PRECIADO, 2014, doc. eletrônico).

Em grande medida, o curso de uma filosofia da informação contemporânea tem se direcionado justamente para esse lugar: a tensão da sobreposição mundo animado \& mundo inanimado. É o caso da crítica de Frohmann (2000) sobre o reconhecimento do(s) corpo(s) e da materialidade da 
informação contra uma disciplina moral do silêncio dos bits. Do mesmo modo, encontramos em Capurro (2017) um percurso aproximado, em sua crítica a uma ética robótica limiar, que isola o sujeito e o mundo das coisas no meio digital e nas demais arenas de atuação dos fatos maquínicos ou, poderíamos dizer, das dinâmicas wienerianas. Na visão capurriana, a separação de uma perspectiva ética do fato maquínico e outra, de fundo humano, parece inconcebível, e não atenta às transformações (como é o caso da "presença" do big data em nosso cotidiano).

Perceber que o "e" que se coloca entre pessoas e coisas pode afastar o debate e promover, outra vez, o falso mito das neutralidades, nos faz pensar no jogo de relações dos artefatos na cena contemporânea (de onde provém uma robética) na visão de Capurro (2017). A interculturalidade seria, aqui, nessa revisão de uma teoria da informação wieneriana, o elemento interpretativo do real construído pelas interações, um real nunca concluído, aberto, ou seja, o uso compreensivo, crítico e revolucionário dos aparatos sociais.

No intuito de promovermos o reencontro entre homens e máquinas, para além dos legados servis produzidos do iluminismo à globalização, vale resgatarmos o pensamento de Simondon:

É difícil tornar se livre transferindo a escravidão a outros seres, sejam homens, animais ou máquinas; reinar sobre um povo de máquina que converte em servo o mundo inteiro segue sendo reinar, e todo reino supõe a aceitação de esquemas de servidão. (SIMONDON, 2008, p.21).

Em sua obra, o autor mergulha no conceito de individuação, tecendo um contraponto à noção antropocêntrica que concebe os indivíduos como seres finalizados em si mesmos; e máquinas restritas a uma lógica instrumental.

Em Simondon, é clarividente a força da crítica à teoria substancialista do ser e ao dualismo hilemórfico do indivíduo, na medida em que ambas as tradições refletem a individuação antes do processo pré-individual, ou seja, enxergam-na a partir de um indivíduo finalizado/pronto, ao passo que, para o autor, ela acontece nos devires, confrontando-se à hipótese de "uma essência, ou de uma substância imutável, sem gênese verdadeira nem porvir autêntico" (DAMASCENO, 2007, p. 174). 
Na concepção de Simondon, os objetos técnicos também deixam de lado as abordagens clássicas, inscritas, por exemplo, no paradigma da física newtoniana e dos parâmetros científicos modernos, baseados em sistemas fechados. Como alerta Neves (20082007, p. 67-68):

não se pode reduzir o desenvolvimento das formas técnicas a partir do projeto da sociedade industrial nem da expansão do mercado. Os objectos técnicos [de acordo com Simondon] individualizam-se movidos pela tendência à concretização e tendem a formar conjuntos complexos de acordo com o movimento de interconexão técnica entre os diferentes indivíduos.

Ao resgatar a cibernética de Wiener (1950) para pensar os seres humanos, os objetos técnicos, a produção de informação e, por que não, de conhecimento, Simondon distorce, como sublinhamos anteriormente, a ideia original de individuação como organização individual dada, destacando a potência dos processos de contato e mediações - ou seja "a informação como potência relacional que fornece uma resolução a uma tensão pré-individual e viabiliza uma integração" (BELISÁRIO, 2015, p. 273).

Logo, o que parece chamar a atenção de Simondon é, justamente, a grande lacuna deixada pela cibernética de Wiener (ora, no rigor de sua teoria, a cibernética "reanima", de um lado, o delírio de um humanismo pautado na ética protestante e na consagração da técnica, bem como "refunda", de outro, um positivismo fervoroso onde a razão encontra a probabilidade, mais precisamente, um neopositivismo, e sua centralidade na linguagem, dentro da qual a informação se torna conceito e matéria).

Com Simondon, percebemos que está ausente, no projeto wieneriano, o entendimento da reversibilidade da recepção e da emissão de informação, que concebe os significados nos complexos processos mediados entre partes heterogêneas (BELISÁRIO, 2015, p. 273). Nesse ponto, Deleuze e Guattari (1997, p. 141) traçam um interessante paralelo entre Simondon e Hursserl:

Tal como dizia Husserl, há o hábito de pensar em termos de essências formais e das coisas sensíveis formadas. Ora, essa tradição esquece uma coisa, o que está entre os dois: um intermediário. É ao nível deste intermediário que tudo se faz, na medida em que nada se pode compreender das essências formais e das coisas formadas, se 
não se focaliza essa região escondida das essências vagas. Simondon diz algo que é estranhamente semelhante. [...] O domínio que Simondon descobre entre a forma e a matéria não é um intermediário que retém um aspecto da forma e um aspecto da matéria, não é de todo uma síntese. É realmente uma terra desconhecida, escondida por essa coisa do intermediário.

Conforme observamos, os autores resgatam o ponto nodal Simondoniano que atenta para a primazia dos encontros, e para a infinidade da diversidade nos eventos de dentro e fora, que aparecem e desaparecem sucessiva e simultaneamente. Composições capazes de produzir quaisquer configurações para os devires - potência geradora da vida. Desse modo, podemos afirmar que somos tecidos entre proximidades e afastamentos, matéria e energia que constantemente atravessam-se e atualizam-se nos esteios da individuação. O exercício teórico inaugurado por Simondon e alargado por Deleuze e Guattari nos oferece, então, as possibilidades de investigação contidas no caráter fluído das relações entre objetos técnicos e humanos, que por todo tempo são transformadas e ressignificadas em seus movimentos de contato.

Neste ínterim, cabe a pergunta: em que medida nós nos aproximamos das máquinas? Apesar de, não raro, acompanharmos enquadramentos binários sobre a existência e atividade dos homens e das máquinas em que "ou se antropomorfiza a máquina, ou se mecaniza o humano" (SANTOS, 2005, p. 166), já explicitamos nas linhas acima como o processo de individuação das máquinas está embutido de componente humano, assim como há muito de maquínico nos agenciamentos que nós, seres humanos, fazemos em nossas relações com o externo.

Logo, reafirmamos o ponto chave da questão não em termos de oposições excludentes, mas pela investigação de:

[...] um tipo de individuação que se dá junto com o processo de individuação das máquinas [ou]: de que maneira, ao nos individuarmos, atualizamos uma potência virtual com as máquinas, que então também atualizam virtualidades que pertenciam ao terreno do pré-individual. (SANTOS, 2005, p. 166, grifo do autor).

Finalmente, emerge a possibilidade de concebermos a técnica não como dispositivo totalizador de dominação global, mas como multiplicidade incessante de encontros e confrontos em perpétua reconfiguração. Tal margem 
nos permite, assim, atentarmos para a produção dinâmica, mas não enclausurada ou destrutiva da técnica. Sem dúvida, o projeto hegemônico de modernidade ocidental nunca chegou a desatar todas as potencialidades da técnica justamente porque se limitou a dar visibilidade às noções de progresso tecnológico orientadas pelo modo de produção e acumulação capitalista, tendo sido escamoteadas diferentes possibilidades de relações.

Por essas razões, pensar a técnica a partir de Simondon, Deleuze e Guattari implica tratar "processos libertos", com o abandono dos limites das representações, que tendem a submeter a diversidade dos corpos a unidades estáticas. Como se verá, é essa perspectiva tornada plástica que anima as apropriações realizadas pelo movimento zapatista de libertação nacional.

\section{0 hibridismo zapatista}

Mesmo diante de inúmeras ameaças às terras comunais sob o argumento de modernização, compartilhado pelos sucessivos governos mexicanos desde a deflagração do processo autonômico em Chiapas, acompanhamos os zapatistas de diferentes comunidades investindo, cada vez mais, no desenvolvimento de formas solidárias de produção e comércio que, mesmo que extremamente vinculadas às tradições e aos costumes locais, apresentam um alto grau de inovação e criatividade. Segundo Sarita Albagli:

É a partir das disputas entre lógicas, cosmovisões, interesses e perspectivas distintas que se impõem uma ou outra inovações. Aquilo que se apresenta como "verdade" é, de fato, aquela [verdade] do poder e do tipo de saber que ele produz, resultado, sempre provisório, de diferenças e antagonismos entre forças e visões de mundo. No capitalismo trata-se centralmente do conflito entre capital e trabalho. Mas também de antagonismos entre paradigmas de desenvolvimento distintos, que se expressam igualmente em distintas matrizes tecnológicas e de inovação. Por exemplo, as diferenças entre a agricultura química, desde a chamada Revolução Verde, de um lado, e as técnicas da agricultura familiar, de outro [...] (ALBAGLI, 2014, p. 213).

Assim, foram gestados os "sistemas autônomos de saúde, baseados na medicina tradicional das comunidades - como serviço de parteiras, curandeiras, ervas medicinais e 'hueseros' (que tratam ossos e membros fraturados)" 
(MARQUES, 2014, p. 67) -, e que também recebem contribuições de médicos urbanos e estudantes de medicina das mais diferentes regiões - do México e do mundo - dispostos a cruzar experiências e intercambiar saberes com as comunidades. A declaração do historiador Antônio Marques, aluno na "Escuelita Zapatista", no ano de 2013, sintetiza bem essa realidade:

Pude observar alguns exemplos de saúde autônoma, como a existência de um laboratório de prótese dental no "Caracol" La Realidad, durante a semana de atividades da "Escuelita". No "Caracol" La Garrucha, onde estive presente nas festas de comemoração dos dez anos dos "Caracóis", na abertura da semana da "Escuelita", conheci uma grande clínica de saúde da mulher, chamada Comandanta Ramona, que é referência na zona e onde se tratam mulheres, independente da sua filiação ou não ao movimento. Suas escolas e clínicas autônomas se desenvolveram a ponto de muitas vezes serem maiores e melhores que as oficiais, onde frequentam inclusive médicos e famílias não-zapatistas. (MARQUES, 2014, p. 67).

A discussão sobre a matriz energética em comunidade parceira, na região de Alto Basas, também é bastante ilustrativa para apreciarmos a maneira coletiva de fazer política (e construir novas possibilidades de futuro!) a partir da conjugação de diferentes cosmovisões.

Antes do levante zapatista de 1994, já tramitava um projeto governamental que previa a criação de seis usinas hidroelétricas para a região, ignorando as reivindicações e necessidades dos habitantes. Movimentando a imensa rede em que estavam inseridos, os indígenas mobilizaram pesquisadores externos, cientistas aclamados de diferentes partes, e líderes comunitários, para apontar as muitas irregularidades na proposta oficial. Confrontaram, assim, dois ideais de modernidade, pondo em "xeque" as formas com que as instituições oficiais se relacionavam com os povos locais.

Nessa empreitada, acabaram por comprovar um grande histórico de falhas no projeto do "mau governo", com a primeira usina, El Caracol - que já estava em funcionamento -, apresentando graves problemas. Os erros de construção e a falta de manutenção por parte das autoridades haviam criado o risco de que, em pouco tempo, El Caracol se tornasse um grande pântano, e deixasse de cumprir a função para que fora criada, que era gerar energia. (POLANCO, 2007) 
Não obstante, o governo tentava impor, a qualquer custo, a instalação da segunda usina, São Juan Tetelcingo, que continuaria a empobrecer a terra, retirando os sedimentos necessários para o cultivo de alimentos e barrando a garantia de autossustento das comunidades (POLANCO, 2007).

Orientando a ideia do governo para a região, estava a movimentação dos mercados, que operavam a tecnologia sem nenhuma consideração dos impactos ambientais e sociais. Porém, múltiplas contribuições somaram-se ao argumento dos indígenas para a construção de proposta dissidente, sem os altos danos do projeto oficial, e com benefícios muito maiores a longo prazo.

$\mathrm{Na}$ maioria das vezes, os interesses hegemônicos - obedientes apenas à especulação do capital - e suas justificativas que englobam ciência e política mostram-se alheios à diversidade de fatores e culturas que constituem a realidade, optando sempre pelo caminho mais destrutivo. Por isso, em situações em que emergem proposições alternativas, não são raros os desvios de uma ciência acabada e suas caixas pretas para que sejam priorizados os processos, as construções. Trata-se de reabrirmos conclusões, dando espaço às intensidades individuantes e às produções de devires - nas quais os diversos atores, por meio de traduções (fundação de elos capazes de transformar os elementos associados), conseguem criar novas potencialidades, amalgamando práticas científicas, saberes tradicionais e diferentes cosmovisões em um alargado panorama de mobilização em que se misturam humanos e objetos técnicos ${ }^{2}$.

Uma das características mais interessantes do movimento de Alto Balsas é, justamente, sua rejeição à lógica binária, que opõe, em extremos opostos, os costumes tradicionais e as estratégias de modernização. Ao invés de respostas tecnofóbicas ou tecnofílicas, construiu-se uma proposta plural, capaz de mediar opiniões técnicas de "cientistas autorizados", das comunidades ao entorno, assim como da própria oficialidade. Está em jogo, no plano de uma teoria da informação, a materialidade dos signos e das formas simbólicas presentes no debate de Frohmann (2000), ou seja, o ponto de vista de uma teoria do documento (que também pode ser compreendida como uma teoria do corpo) que se impõe sobre uma teoria da informação. Do mesmo modo, também em cena, está um plano da interculturalidade para os dilemas éticos e da injustiça social sob as lentes das dinâmicas informacionais, como podemos perceber em 
Capurro (2017), centrado na vivência dos modos locais de intepretação e de criação do real a partir de objetos. Enquanto a ciência moderna se mobiliza pela “desanimação" do mundo, os indígenas evocam a pluralidade das individuações humanas e não humanas, reconhecendo-as em suas potencialidades de interação e transformação do real, através do cruzamento entre corpos e mundos distintos.

O resultado foi um projeto sustentável, apropriando a tecnologia à tradição local. A partir de um diálogo com o governo, do autodiagnóstico da população, e da assessoria técnica externa, os indígenas lideraram a iniciativa para a construção de diversas pequenas represas com baixo custo social, cultural e ambiental, o que permitiu o fortalecimento de esquemas próprios de desenvolvimento na vida agrícola, artesanal e comercial de Alto Balsas (POLANCO, 2007). Além do cuidado com a natureza, com a cultura e com os costumes regionais, eles estimularam a produção de recursos para a construção de autonomia em relação aos poderes centrais.

Como observamos, os indígenas revelaram estratégias originais, que não conservam as estruturas pré-modernas de maneira intocável, e incorporam a tecnologia de modo sustentável e proveitoso ao seu processo autonômico.

Apesar de ainda nos faltar pesquisa mais densa, não consideramos arbitrária a aproximação dos zapatistas ao domínio da chamada "tecnomagia", que investiga, justamente, a interpenetração entre tecnologia e cosmovisões.

[...] não se separa os indivíduos da tecnologia que se utilizam. Ao invés da ênfase no valor instrumental da técnica, e sua relação com a consciência individual ou social das pessoas, que ataca a separação da indústria do dano que causa ao ambiente, compreende a lógica de manutenção do lucro e proporciona alternativas para desempregados, comunidades, artistas... exploraremos a continuidade entre técnica e cultura enquanto modo privilegiado de apreensão de uma realidade tecnomágica, buscando no acoplamento humano-máquina a melhor descrição do fenômeno híbrido que tomamos para análise. Ao assumir a ideia de híbrido, alguns pressupostos, notadamente ontológicos, são questionados. O pano de fundo coincide com a crítica ao pensamento cartesiano, à ideia de cogito que parte de indivíduos-átomos, atacando ao mesmo tempo uma certa construção do social que tratou basicamente de considerar o comportamento dos humanos como objeto de análise. Entenda-se por híbrido, portanto, a mistura entre elementos antes considerados de distintas naturezas, refundando mesmo a natureza com suas leis imutáveis, e também o social, com seus indivíduos coagidos por leis sociais. (NOVAES, 2013, doc. eletrônico). 
Como bem ressalta Belisário, nessa relação tecnomágica misturam-se as potências de saberes e técnicas há muito menosprezados, com novas tecnologias que, de maneira geral, têm sido usadas pelo establishment para produzir expropriações e explorações de todo o tipo. Logo, a convergência entre as diferentes maneiras de conhecer apontam para um uso mais respeitoso e equilibrado dos saberes, no sentido de reparação das capturas do capitalismo globalizado conduzidas por um "evolucionismo" castrador.

ao invés de corporações, cooperações. No lugar de patentes, a gambiarra e a produção de recursos comuns. É uma tentativa de juntar duas formas de conhecimentos que são constantemente separadas. A bruxa e o cientista. O curandeiro e o médico. A feiticeira e o robô. A convergência entre técnica e xamanismo é um investimento de reparação de erros antigos de má distribuição de saberes e julgamentos deterministas precipitados a respeito das formas de conhecimento. (BELISÁRIO, 2015, p. 278).

O uso da técnica, aqui, faz-se, deste modo, não apenas como crítica negativa (e necessária) de propensos "espantalhos" do mundo tecnológico, mas uma crítica aos próprios modos de elaboração e apropriação de técnicas como parte do humano, e não um elemento externo, portador de vida ou de morte. Como lembra Vieira Pinto, "Se algum maniquismo, numa historieta de ficção científica, se pusesse a fabricar algo não desejado, o homem imediatamente destruiria a importuna engenhoca e poria fim à indesejável 'escolha aleatória'." (2005, p. 527).

A luta social, é, pois, não uma luta contra coisas ou deuses, mas contra uma concretude que se estabelece sob a forma de deuses e coisas. A apropriação de ambas, o Deus-máquina, e/ou a ferramenta sagrada, não representa um modo arcaico de arte da guerra, mas uma dinâmica das condições sociais sob as quais se estabelecem as relações entre homens e objetos técnicos (se é que podemos falar de "relações", posto que o termo sugere, a priori, ora certo distanciamento, ora certo encontro, mas nunca uma "unidade"; "unidade" através da qual, segundo a leitura casseriana das formas simbólicas, diferentes sociedades e diferentes classes sociais, nos mais diferentes quadros do espaço-tempo, identificaram, adotaram, adaptaram e reinventaram como "técnica" a noção 
círculo, por exemplo, noção-ferramenta esta revolucionária, da Antiguidade ao mundo contemporâneo.)

\section{Considerações finais: lutas simbólicas para muito além da abordagem wieneriana}

Da guerrilha armada ao massivo movimento social; das técnicas tradicionais às novas tecnologias de produção e informação; os indígenas de Chiapas se articulam para construir sua autonomia em relação aos poderes oficiais mexicanos, e para disputar o projeto de desenvolvimento regional. O processo de luta se dá pelo reforço de sua alteridade e denúncia do discurso oficial que, sob a retórica da modernização, com o uso da tecnologia atrelado às capturas do capitalismo global, avança sob seu território e subjuga a população e os costumes locais.

Tanto em seu processo cotidiano de autogestão - que incentiva a intensa participação popular e a aproximação de várias pessoas e movimentos sociais ao redor do mundo - como nos usos criativos que fazem da tecnologia, a partir dos saberes locais, conhecimentos externos adquiridos, e da atuação comunitária em uma interação tecnohumana permanentemente aberta, os zapatistas logram visão e ação de mundo ampliadas, relacionadas com a natureza e a tecnologia, a imaginação e o trabalho, as tradições e os novos saberes ocupando lugares simétricos para a luta por um novo mundo possível. Nesse contexto, uma abordagem wieneriana para a teoria da informação pouco contribui para a compreensão de tais dinâmicas simbólicas. A construção de uma teoria da informação crítica recebe, no solo empírico das experimentações e dos construtos zapatistas, o diálogo dos corpos e da interculturalidade como categorias indissociáveis da informação. Dentre tantas revisões da teoria da informação construídas pós-meados do século $\mathrm{XX}$, encontramos, pois, nos diálogos de Frohmann (2000) e Capurro (2017), fontes objetivas para a interpretação dessas dinâmicas, assim como em todo o pensamento Simondoniano.

Um novo mundo também para as ciências sociais que, cada vez mais, surpreendem-se com a emergência de racionalidades outras, questionadoras das 
clausuras do cientificismo moderno, e obrigam-se a ampliar suas lupas de investigação para a pluralidade das culturas; para a mescla entre "tradições" e "modernidades", e para os devires plásticos potencializados na interação entre humanos e objetos técnicos na tessitura da realidade.

\section{Referências}

ALBAGLI, Sarita. Inovação no capitalismo cognitivo. In: SIQUEIRA, Mauricio; COCCO, Giuseppe (org.). Por uma política menor: arte, comum e multidão. Rio de Janeiro: Fundação Casa de Rui Barbosa, 2014. p. 211-224.

BELISÁRIO, Adriano. Tecnoxamanismo: por uma cibernética insurgente. Lugar Comum, [s.l.], v. 43, p. 265-280, 2015.

CAPURRO, Rafael. Intercultural Roboethics for a Robot Age. In.: NAKADA, Makoto; CAPURRO, Rafael; SATO, Koetsu. Critical review of information ethics and roboethics in East and West. Tsukuba: University of Tsukuba, 2017. p. 13-18.

CASSIRER, Ernst. A filosofia das formas simbólicas. Segunda parte: o pensamento mítico. São Paulo: Martins Fontes, 2004.

DAMASCENO, Veronica. Notas sobre individuação intensiva em Simondon e Deleuze. O que nos faz pensar, [s.l.], v. 16, n. 21, p. 169-182, jul. 2007.

DELEUZE, Giles; GUARATTARI, Felix. Mil platôs: capitalismo e esquizofrenia. São Paulo: Editora 34, 1997.

DERRIDA, Jacques. Gramatologia. São Paulo: Perspectiva, 2008.

FROHMANN, Bernd. Cyber ethics: bodies or bytes? The International Information \& Library Review, [s.l.] n. 32, p. 423-435, 2000.

LATOUR, Bruno. A esperança de Pandora: ensaios sobre a realidade dos estudos científicos. Bauru: EDUSC, 2001.

MARQUES, Luis Antonio Barbosa Guerra. Democracia, Justiça, Liberdade: lições da Escuelita Zapatista. 2014. Dissertação (Mestrado em Sociologia) Universidade de Brasília, Brasília, 2014.

NEVES, José. Seres humanos e objectos técnicos: a noção de "concretização" em Gilbert Simondon. Comunicação e Sociedade, [s.l.], v.12, p. 67-82, 2007.

NOVAES, Thiago. Tecnomagia: metareciclagem e rádios livres no front de uma guerra ontológica. Fórum Permanente, [s.l.], v. 2, n. 2, 2013. 
POLANCO, Héctor Díaz. La Rebelión Zapatista y La Atonomía. México: Siglo XXI Editores, 2007.

PRECIADO, Beatriz. El feminismo no es un humanismo. El Estado Mental, Madrid, n. 5, nov. 2014.

SANTOS, Laymert Garcia. Demasiadamente pós-humano. Entrevista com Laymert Garcia dos Santos. Novos estudos, São Paulo, n. 72, p. 161-175, jul. 2005.

SIMONDON, Gilbert. El modo de existencia de los objetos técnicos. Buenos Aires: Prometeo Libros, 2008.

TADEU, Tomaz. Nós ciborgues: o corpo elétrico e a dissolução do humano. In: HARAWAY, Donna; KUNZRU, Hari; TADEU, Tomaz (orgs.). Antropologia do ciborgue: as vertigens do pós-humano. Belo Horizonte: Autêntica Editora, 2009.

VIEIRA PINTO, Álvaro. O conceito de tecnologia. Rio de Janeiro: Contraponto, 2005.

WIENER, Norbert. Cibernética e sociedade: o uso humano de seres humanos. 2. ed. São Paulo: Editora Cultrix, 1950.

\title{
Technicality, information theory and tradition in the zapatista movement of national liberation: the powers of a new possible (informational) world.
}

\begin{abstract}
Starting from a theoretical reflection with an empirical contribution of the social world understanding, the work intends to bring the questions that guide the poles from technophobia to technophilia, or to pan-technique, in the contemporary world. Originating mainly from Simondon's philosophy, the theoretical axis aims to understand a notion of technique driven by the primacy of encounters and to the infinity of diversity in the events inside and outside, which appear and disappear successively and simultaneously in the informational plane. An "information" Simondonian theory opens up the margins of compositions capable of producing any configurations for becomings - the life-generating power, that is, the texture between proximities and distances, matter and energy that constantly cross and update themselves on the individuation mainstays of human and non-human. The empirical axis finds in the Zapatista experience, that is, in the production of an autonomic guerrilla, an original and open relationship, like the Simondonian view of technique, which does not maintain the pre-capitalist past or the premodern structures as untouchable. It is a matter of recognizing technomagic as a possibility of investigation within the interpenetration between technology and cosmovisions,
\end{abstract}


a theoretical-social movement of a community in its struggle against domination and institutionalized oppression.

Keywords: Technicality. Information. Simondon. The Zapatista Movement. Technomagic.

Recebido: 25/09/2017

Aceito: 02/09/2018

${ }^{1} \mathrm{O}$ governo oficial é chamado pelos indígenas zapatistas e pelas comunidades apoiadoras do movimento de "mau governo", em contraste com as juntas do "bom governo", criadas pelas comunidades autônomas.

${ }^{2}$ Para além de Simondon, ver Latour (2001). 